\title{
Histopathological picture of pancreatic islets in dogs with congenital portosystemic shunt ${ }^{1)}$
}

\author{
JAN FRYMUS, PIOTR TRĘBACZ, MAŁGORZATA SOBCZAK-FILIPIAK*, \\ MICHAŁ CZOPOWICZ ${ }^{* *}$, BEATA DEGÓRSKA, MAREK GALANTY
}

\begin{abstract}
Department of Small Animal Diseases with Clinic, *Department of Pathology and Veterinary Diagnostics, **Laboratory of Veterinary Epidemiology and Economics, Faculty of Veterinary Medicine, Warsaw University of Life Sciences - SGGW, Nowoursynowska 159c, 02-776 Warsaw, Poland
\end{abstract}

Frymus J., Trębacz P., Sobczak-Filipiak M., Czopowicz M., Degórska B., Galanty M. Histopathological picture of pancreatic islets in dogs with congenital portosystemic shunt

Summary

Hypoglycemia is frequently found in dogs suffering from portosystemic shunt (PSS). However, the mechanisms leading to abnormal blood glucose concentration in such dogs have not been studied. Therefore, investigations were undertaken to study the structure of pancreatic islets in 25 patients with congenital PSS (cPSS). Material for morphometry and histopathology was taken during the surgical closing of the abnormal blood vessel. A total of 75 islets (3 randomly chosen from each patient) were analyzed, and their average size was compared to reference values for dogs that were considered as 50-325 $\mu \mathrm{m}$. The average size of $47(63 \%)$ islets was below $50 \mu \mathrm{m}$, whereas the mean dimension of the largest islet did not exceeded $80 \mu \mathrm{m}$. The average islet size in all patients was 46 (SD 13.3) $\mu \mathrm{m}$ and in only 2 dogs (8\%) all 3 analyzed islets were bigger than the lower reference value. Histopathological examination revealed cytoplasmic vesicles in pancreatic cells, as well as extracellular, homogenous, acidophilic deposits in pancreatic islets. These results indicate that in dogs suffering from cPSS the pancreatic islets are smaller than the reference values and their cells may contain abnormal structures.

Keywords: Portosystemic shunts, hypoglycemia, pancreas

Besides the normal arterial supply, the liver receives from the portal vein blood containing nutrients from digested food absorbed in the intestines. One of many liver functions is the elimination of toxic substances derived from the gastrointestinal tract. Portosystemic shunt (PSS) is a life threatening condition where due to abnormal connection(s) the portal blood bypasses the liver, thus transporting blood directly to the caudal vena cava. In dogs, it is usually a congenital problem (cPSS) resulting in severe liver dysfunction and complications affecting other organs. The most prominent are clinical signs from the gastrointestinal tract - vomiting and diarrhea - but also from the urinary system, like polydipsia, polyuria, and urolithliasis (3). Usually they are accompanied by neurological disorders resulting from hepatic encephalopathy, which develops due to the increasing concentrations of certain neurotoxins in the blood, predominantly ammonia. Hepatic encephalopathy in dogs with PSS is used as a model of this disease in humans (15). In dogs suffering from PSS only hepatic failure was investigated so far, and many

${ }^{1)}$ Wyróżnienie za najlepszą pracę przedstawioną przez młodych pracowników nauki w Sekcji chorób psów i kotów podczas XV Kongresu PTNW w Lublinie 22-24 września 2016 r. morphological and functional liver disorders have been identified $(1,13)$.

Most dogs with PSS have hypoglycemia $(2,3,5)$, which means a blood glucose level below $3.9 \mathrm{mmol} / 1$ (70 mg/dl) (16). Hypoglycemia may result from excessive consumption of glucose by the tissues or from a decreased release of glucose into blood. Liver initially converting glucose to glycogen, followed by its breakdown, is the main source of blood glucose. Therefore, liver damage can result in hypoglycemia. On the other hand, the pancreas is the major organ regulating the glucose level in blood.

The endocrine function of the pancreas is related to the pancreatic islets (formerly islets of Langerhans) dispersed throughout the organ. They contain four types of cells, namely: A, B, D and PP. Type A cells secrete glucagon which elevates the blood glucose level. Type $\mathrm{B}$ cells are most numerous, and produce insulin which lowers the blood glucose level. Type D cells are low in number. They secrete somatostatin which is known to inhibit the secretion of both glucagon and insulin, so they are considered as regulatory cells. PP cells produce a pancreatic polypeptide also having different regulatory functions (7). The structure of islets is not 
static but changes in response to normal physiology and pathophysiology such as diabetes mellitus, pregnancy, obesity (14). In young dogs (6 months), type B cells are most numerous, representing $52-82 \%$ of the total islet cells, and their amount is constant, in contrast to percentages of A and PP cells that differ depending on the region (9). The size of the islets in healthy dogs ranges from 50 to $325 \mu \mathrm{m}(8,10,17)$.

As mentioned, hypoglycemia is frequently found in PSS patients, but there are no data available on possible pancreatic disorders in dogs suffering from this condition. It has been shown that hyperinsulinemia occurs seldom in such patients, thus a need of further studies on this topic has been indicated (2). A rare human condition, nesidoblastosis, characterized by pancreatic islet cell hyperplasia, may lead to hypoglycemia, usually accompanied by central neurological disorders. Recent reports stress that nesidoblastosis should be considered in humans with idiopathic hypoglycemia if the insulin level is inadequate to glycemia $(11,12)$. So far, parallel studies have not been performed in dogs with PSS

Until recently, studies in dogs with PSS have been focused mostly on liver disorders, whereas no substantial data on the pancreas function and morphology have been published. Since both liver and pancreas play a crucial role in maintaining blood glucose level, the aim of the study was to determine the microscopic picture and size of pancreatic islets in dogs with cPSS.

\section{Material and methods}

The study was performed on 25 patients with cPSS. They were of both sexes and different breeds (Yorkshire terrier $32 \%$, Maltese $20 \%$, Shih Tzu 8\%, West Highland White Terrier $8 \%$, Golden Retriever $8 \%$, mixed breed $8 \%$, Jack Russel Terrier 4\%, Papillon 4\%, Fila Brasileiro 4\%, Hovawart 4\%). Their age ranged from 11 to 140 weeks, with the arithmetic mean of 30 . Most (19/25-76\%) were younger than 1 year of age.

Collection of pancreatic fragments. Surgical closing of the abnormal blood vessel is the treatment of choice for patients suffering from cPSS, and during this procedure fragments of the pancreas were obtained. The animals were premedicated i.m. with medetomidine (Cepetor, ScanVet) at a dose of $37.5 \mu \mathrm{g} / \mathrm{kg}$ body weight and butorphanol (Butomidor, RichterPharma) at a dose of $0.3 \mathrm{mg} / \mathrm{kg}$. Inhalation anesthesia was performed with isoflurane (Aerrane). The dogs were placed in a dorsal position, abdominal skin was shaved, and the operating field, including umbilical area, was prepared according to routine procedures. The abdominal cavity has been opened in the white line, and by inspection the pathological shunting vessel was localized and ligated. Then a small fragment of the caudal right lobe of the pancreas was removed using a guillotine knot technique (Fig. 1). The pancreatic fragment was immediately fixed in buffered $10 \%$ formaldehyde and sent for histopathological examination.

Histopathological examination. The fragments were embedded in paraffin (Paraplast plus), and ultrathin slices

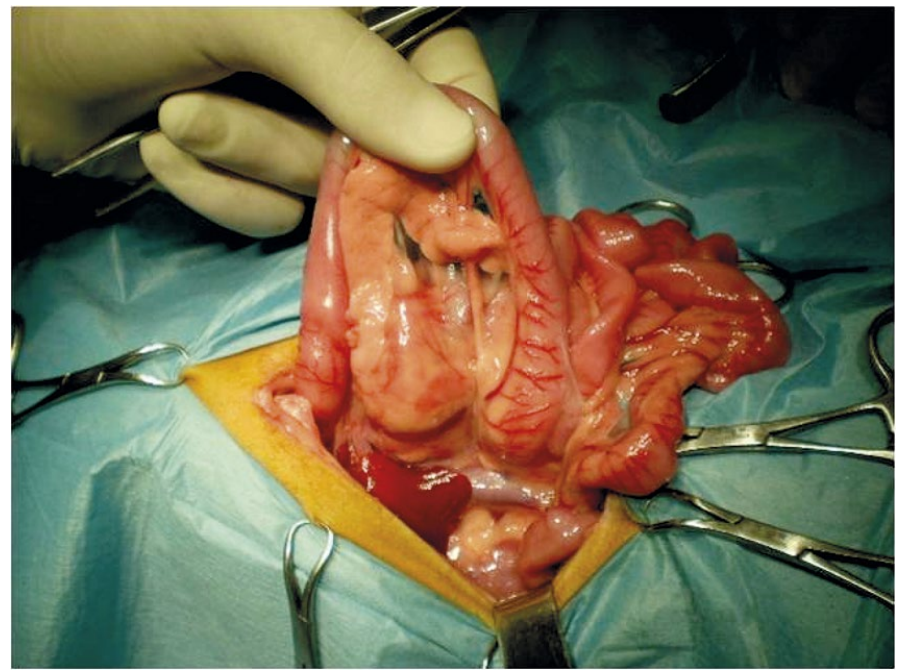

Fig. 1. Intraoperative view of the pancreas before collecting a sample for histopathological examination (caudal right lobe of the pancreas)

$(4 \mu \mathrm{m})$ were cut using a rotational microtome. Microscopic slides were then prepared and stained routinely with hematoxylin/eosin (automatic staining Varistain Gemini Thermo Scientific). Histopathology was performed using a light microscope Olympus BX 43 connected to the computer and SC30 camera. Microscopic analysis was done with the software CellSens Entry 2011, Olympus, and photographic documentation was performed. In all dogs, the length and the width of three, randomly chosen pancreatic islets were measured.

Statistical analysis. Numerical variables were presented as arithmetic mean, standard deviation (SD) and range. 95\% confidence intervals (CI 95\%) were given where applicable.

To determine the shape of a pancreatic islet its length was divided by its width and then the results for three islets of a given dog were averaged, and called the mean roundness coefficient. The shape of the islets was assessed in terms of its roundness using the one-sample Student's t-test where unity was a proxy of a regular round shape. The length and width of the islets were compared between dogs using the Welch's one-way analysis of variance (ANOVA) on account of the significant result of the Levene's test for equality of variances. To compare the islet size with literature reference interval (50-325 $\mu \mathrm{m})$, the average islet dimension was calculated as an arithmetic mean of its length and width. Then the percentage of dogs with average islet dimensions below the lower limit of the reference interval $(50 \mu \mathrm{m})$ was calculated. All statistical tests were two-sided and the significance level $(\alpha)$ was set at 0.05 . Statistical analysis was performed in Statistica 12 (StatSoft, Inc., Tulsa, OK).

\section{Results and discussion}

In $21(84 \%)$ dogs, the pancreatic islet cells in the cytoplasm have been found to contain vesicles of different size (Figs. 2a, 2b). In addition, in 5 patients $(20 \%)$ homogenous acidophilic masses located extracellularly were found. In 1 dog (4\%) connective tissue hyperplasia was seen.

The mean roundness coefficient of the pancreatic islets was 1.41 (CI 95\%: 1.31-1.51), and was 


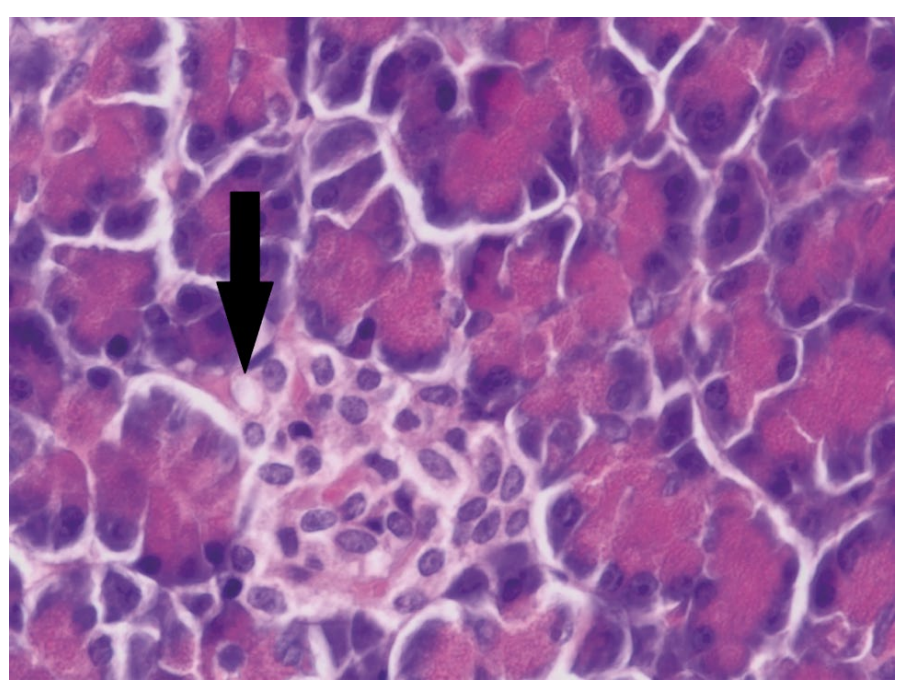

Fig. 2a. Cytoplasmic vacuoles (black arrow) in pancreatic islet cells in a dog with congenital portosystemic shunt (cPSS). Magnification $40 \times$

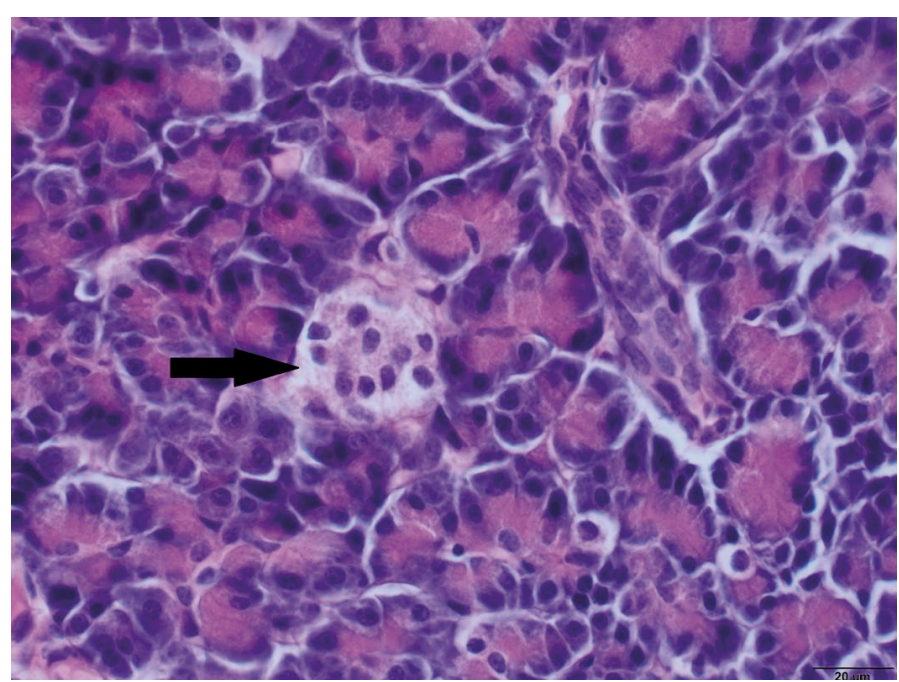

Fig. 2b. Cytoplasmic vacuoles (black arrow) in pancreatic islet cells in a dog with congenital portosystemic shunt (cPSS). Magnification $40 \times$

significantly different from unity $(\mathrm{p}<0.001)$, indicating that the islet shape was not round.

The length of the pancreatic islets ranged from $26.5 \mu \mathrm{m}$ to $108.0 \mu \mathrm{m}$, with the arithmetic mean (SD) of 53.4 (11.2) $\mu \mathrm{m}$ and islet length significantly differed between dogs $(p<0.001)$. The width of pancreatic islets ranged from $16.7 \mu \mathrm{m}$ to $70.4 \mu \mathrm{m}$, with the arithmetic mean (SD) of $38.6(8.8) \mu \mathrm{m}$ and islet width significantly differed between dogs $(\mathrm{p}<0.001)$ as well.

The average islet dimension ranged from 23.7 to $78.0 \mu \mathrm{m}$ with the arithmetic mean (SD) of 46.0 (13.3) $\mu \mathrm{m}$ (Fig. 3). In total, 47 islets $(63 \%)$ had the average dimension below $50 \mu \mathrm{m}$. In 7 dogs $(28 \%)$ the average dimension of all examined islets was below $50 \mu \mathrm{m}$. In 10 patients $(40 \%)$, the average dimension of 2 islets, and in 6 dogs of 1 islet were below the reference interval. The average dimension of all 3 examined islets fell within the reference interval $(50-325 \mu \mathrm{m})$ in only 2 dogs $(8 \%)$ (Tab. 1$)$.

The most frequent and best recognized pancreatic disorder in humans and many animal species is diabetes mellitus. It is a complex group of disturbances in the oxidation and utilization of glucose, secondary to the impaired function of B cells in the pancreas. In humans suffering from this disease, many macroscopic and microscopic lesions have been identified in pancreatic islets as inflammatory infiltration, necrosis, fibrosis, hyalinization and presence of cytoplasmic vesicles containing glycogen in the B cells. Vesicular lesions in $\mathrm{B}$ cells are considered as pathognomonic for diabetes in humans (4). We also found numerous vesicles of

Tab. 1. Number of dogs suffering from congenital portosystemic shunt (cPSS) with average dimensions of pancreatic islets below the reference interval (50-325 $\mu \mathrm{m})$. From each patient 3 randomly chosen islets were measured

\begin{tabular}{|l|c|}
\hline \multicolumn{1}{|c|}{ Average dimensions of the islets } & Number of dogs \\
\hline 3 islets $<50 \mu \mathrm{m}$ & $7(28 \%)$ \\
2 islets $<50 \mu \mathrm{m}$ & $10(40 \%)$ \\
\hline 1 islet $<50 \mu \mathrm{m}$ & $6(24 \%)$ \\
3 islets over $50 \mu \mathrm{m}$ & $2(8 \%)$ \\
\hline
\end{tabular}

different sizes in the cytoplasm of cells in pancreatic islets from dogs with cPSS (Figs. 2a, 2b). However, in contrast to dogs with diabetes mellitus showing hyperglycemia, canine patients with cPSS are usually hypoglycemic. Further studies are necessary to deter- 
mine the content of these vesicular lesions in dogs with cPSS, as well as the type of the cells containing them. However, since up to $82 \%$ of all canine islet cells are classified as type B (9), it seems probable that these cells must have been involved in the vesicular lesions observed in dogs with cPSS. In our patients we also found acidophilic deposits located extracellularly in pancreatic islets. In diabetic humans, pancreatic islets may contain deposits of amyloid, that microscopically are seen as acidophilic masses (6). To determine the character of these deposits in cPSS patients further studies are needed.

Data on the size of pancreatic islets in healthy dogs are scarce. In a study on different isolation procedures of pancreatic islets in 14 healthy dogs the average dimension of islets varied from 50 to $325 \mu \mathrm{m}$, while in $75 \%$ of them it was 100 to $200 \mu \mathrm{m}$ (17). In other studies on healthy beagles and cross-breed dogs the average dimension of pancreatic islets was $50-100 \mu \mathrm{m}(8,10)$. Taking these data into consideration, we decided to assume the reference interval as 50 to $325 \mu \mathrm{m}$. Most of the islets examined in our study proved to be below the lower limit of this interval, and the average dimension of the largest islet did not exceed $80 \mu \mathrm{m}$ (Fig. 3).

Even though our morphometric results indicated that in dogs suffering from cPSS the pancreatic islets are significantly smaller than in healthy animals, the reference intervals assumed in our study may simply be too high. As mentioned above, data from available literature are scarce, and they may not apply to dogs of the breeds or age of patients we enrolled in our study. Therefore, this finding needs to be confirmed by comparison of pancreatic islets found in our patients with the size of these structures in dogs of a similar age free from PSS, as $76 \%$ of our patients were puppies 3 to 12 -months-old. We could not find data on the relation between the dimensions of pancreatic islets and the age of the dogs. Thus, it cannot be excluded that the findings in pancreatic islets observed in our very young patients with cPSS were, at least in part, related to the growth and development of the pancreas in puppies. Therefore, further studies are necessary.

\section{References}

1. Baade S., Aupperle H., Grevel V., Schoon H. A.: Histopathological and immunohistochemical investigations of hepatic lesions associated with congenital portosystemic shunt in dogs. J. Comp. Pathol. 2006, 134, 80-90.

2. Collings A. J., Gow A. G., Marques A., Yool D., Furneaux R., Mellanby R., Watson P. J.: A prospective study of basal insulin concentrations in dogs with congenital portosystemic shunts. J. Small Anim. Pract. 2012, 53, 228-233.

3. Frymus J., Trębacz P., Degórska B., Sterna J., Kowalczyk P., Tomkowicz A., Galanty M.: Portosystemic shunt in dogs and cats. Current diagnostic aspects. Magazyn Wet. 2015, Nov., 12-22 (in Polish).

4. Groniowski J., Kruś S. (ed.): Podstawy patomorfologii. PZWL Warszawa 1991, p. 767-768.

5. Kraun M. B., Nelson L. L., Hauptman J. G., Nelson N. C.: Analysis of the relationship of extrahepatic portosystemic shunt morphology with clinical variables in dogs: 53 cases (2009-2012). J. Am. Vet. Med. Assoc. 2014, 245, 540-549.

6. Kruś S., Skrzypek-Fakhoury E. (ed): Patomorfologia kliniczna. PZWL, Warszawa 2007

7. Kuryszko J., Zarzycki J.: Histologia zwierząt. PWRiL, Warszawa 2000.
8. Lakey J. R., Woods E. J., Zieger M. A., Avila J. G., Geary W. A., Voytik-Harbin $S$. L., Critser J. K.: Improved islet survival and in vitro function using solubilized small intestinal submucosa. Cell Tissue Bank. 2001, 2, 217-224.

9.Muranishi T., Takehana K., Hiratsuka T., Kobayashi A., Eerdunchaolu, Iwasa $K$., Abe M.: An investigation of the relationship between duct system and A cell-rich and PP cell-rich pancreatic islets in the canine pancreas. J. Vet. Med. Sci. 1999, 61, 737-742

10. Nagaya M., Kubota S., Isogai A., Tadokoro M., Akashi K.: Ductular cell proliferation in islet cell neogenesis induced by incomplete ligation of the pancreatic duct in dogs. Surg. Today 2004, 34, 586-592.

11. Przybylik-Mazurek E., Pach D., Hubalewska-DydejczykA., Sowa-StaszczakA., Gilis-Januszewska A., Kulig J., Matyja A., Chrapczyński P.: Symptoms and early diagnostic possibilities of pancreatic endocrine cells hyperplasia (nesidioblastosis). Przegl. Lek. 2012, 69, 9-14 (in Polish).

12. Raffel A., Krausch M. M., Anlauf M., Wieben D., Braunstein S., Klöppel G., Röher H. D., Knoefel W. T.: Diffuse nesidioblastosis as a cause of hyperinsulinemic, hypoglycemia in adults: a diagnostic and therapeutic challenge. Surgery 2007, 141, 179-184.

13. Sobczak-Filipiak M., Męcik-Kronenberg T., Czopowicz M., Galanty M., Trębacz P., Frymus J., Badurek I., Szarek J.: Lipogranulomas and pigment granulomas in livers of dogs with portosystemic shunt. Pol. J. Vet. Sci. 2018, 21, 265-272.

14. Steiner D. J., Kim A., Miller K., Hara M.: Pancreatic islet plasticity: interspecies comparison of islet architecture and composition. Islets. 2010, 2, 135-145.

15. Tivers M. S., Handel I., Gow A. G., Lipscomb V. J.: Attenuation of congenital portosystemic shunt reduces inflammation in dogs. PLoS One. 2015, 10, 2, doi.org/10.1371/journal.pone.0117557.

16. Winnicka A.: Wartości referencyjne podstawowych badań laboratoryjnych w weterynarii. Wydawnictwo SGGW, Warszawa 2008, p. 55-56.

17. Woolcott O. O., Bergman R. N., Richey J. M., Kirkman E. L., Harrison L. N., Ionut V., Lottati M., Zheng D., Hsu I. R., Stefanovski D., Kabir M., Kim S. P., Catalano K. J., Chiu J. D., Chow R. H.: Simplified method to isolate highly pure canine pancreatic islets. Pancreas 2012, 41, 31-38.

Corresponding author: Jan Frymus, DVM, ul. Nowoursynowska 159c, 02-776 Warszawa, Poland; e-mail: janfrymus@wp.pl 